\title{
Refinement of the Symptom Screening in Pediatrics Tool (SSPedi)
}

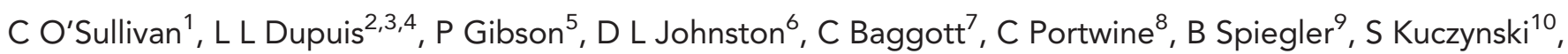
D Tomlinson ${ }^{1}$, S de Mol Van Otterloo ${ }^{1}, \mathrm{G}$ A Tomlinson ${ }^{11}$ and L Sung ${ }^{\star, 1,2}$

${ }^{1}$ Program in Child Health Evaluative Sciences, The Hospital for Sick Children, Peter Gilgan Centre for Research and Learning, 686 Bay Street, Toronto, Ontario M5G OA4, Canada; ${ }^{2}$ Division of Haematology/Oncology, The Hospital for Sick Children, 555 University Avenue, Toronto, Ontario M5G 1X8, Canada; ${ }^{3}$ Department of Pharmacy, The Hospital for Sick Children, 555 University Avenue, Toronto, Ontario M5G 1X8, Canada; ${ }^{4}$ Leslie Dan Faculty of Pharmacy, University of Toronto, 144 College Street, Toronto, Ontario M5S 3M2, Canada; ${ }^{5}$ Division of Haematology/Oncology, Department of Pediatrics, London Health Sciences Centre, 800 Commissioners Road East, London, Ontario N6A 5W9, Canada; 'Division of Hematology/Oncology, Children's Hospital of Eastern Ontario, 401 Smyth Road, Ottawa, Ontario K1H 8L1, Canada; ${ }^{7}$ School of Nursing, UCSF Medical Center, Parnassus, 2 Koret Way, San Francisco, California 94143, USA; ${ }^{8}$ Division of Haematology/Oncology, McMaster Children's Hospital, Health Sciences Centre, 1280 Main Street West, Hamilton, Ontario L8S 4K1, Canada; ${ }^{9}$ Department of Psychology, The Hospital for Sick Children, 555 University Avenue, Toronto, Ontario M5G 1X8, Canada; ${ }^{10}$ Ontario Parents Advocating for Children With Cancer (OPACC), 99 Citation Drive, Toronto, Ontario M2K 1S9, Canada and ${ }^{11}$ Department of Medicine, Toronto General Hospital, 200 Elizabeth Street, Toronto, Ontario M5G 2C4, Canada

Background: Objective was to evaluate and refine a new instrument for paediatric cancer symptom screening named the Symptom Screening in Pediatrics Tool (SSPedi).

Methods: Respondents were children 8-18 years of age undergoing active cancer treatment and parents of eligible children. Respondents completed SSPedi once and then responded to semi-structured questions. They rated how easy or difficult SSPedi was to complete. For items containing two concepts, we asked respondents whether concepts should remain together or be separated into two questions. We also asked about each item's importance and whether items were missing. Cognitive probing was conducted in children to evaluate their understanding of items and the response scale. After each group of 10 children and 10 parents, responses were reviewed to determine whether modifications were required. Recruitment ceased with the first group of 10 children in which modifications were not required.

Results: Thirty children and 20 parents were required to achieve a final version of SSPedi. Fifteen items remain in the final version; the score ranges from 0 to 60 .

Conclusions: Using opinions of children with cancer and parents of paediatric cancer patients, we successfully developed a symptom screening tool that is easy to complete, is understandable and demonstrates content validity.

Cure rates for paediatric cancer are approaching 82\% (Canadian Cancer Society's Steering Committee on Cancer Statistics, 2011) but the costs of this progress include a high frequency and intensity of symptoms during treatment (Baggott et al, 2010; Poder et al, 2010; Miller et al, 2011) and chronic health conditions following completion of treatment (Oeffinger et al, 2006). In general, the symptom burden in children undergoing treatment for cancer is very high (Baggott et al, 2010; Poder et al, 2010; Miller et al, 2011). Active symptom screening is important because children undergoing cancer treatment may not voice concerns or complain.

*Correspondence: Dr L Sung; E-mail: lillian.sung@sickkids.ca

Received 2 May 2014; revised 4 July 2014; accepted 13 July 2014; published online 7 August 2014

(c) 2014 Cancer Research UK. All rights reserved 0007-0920/14 
They may accept symptoms as an inevitable consequence of chemotherapy, only seeking help when the symptoms become severe (Woodgate, 2003; Gibson et al, 2010). It is important to identify symptoms by self-report as opposed to by proxy report. Identification of symptoms by the child, most especially subjective symptoms, ensures that the perspectives and experiences of the child are being captured and that the attention of clinicians and parents is focused on the symptoms most important to that child.

Within the adult oncology setting, screening and assessment of symptoms through patient self-report has been identified as an important priority (Coates et al, 1983; Griffin et al, 1996; de BoerDennert et al, 1997; Carelle et al, 2002). Efforts by Cancer Care Ontario (CCO) have culminated in the widespread use of a symptom screening tool based upon the Edmonton Symptom Assessment Scale (ESAS; Bruera et al, 1991). The ESAS is a validated tool that asks adult patients to rate the severity of nine common symptoms including pain, anxiety and nausea. In a satisfaction survey of 2921 patients, $87 \%$ of respondents thought the ESAS was an important tool for letting healthcare providers know how they feel (Cancer Care Ontario, 2011). Furthermore, through an initiative with $\mathrm{CCO}$ and the Canadian Partnership Against Cancer, evidence-based guidelines were developed to manage severe symptoms identified by the tool (Cancer Care Ontario, 2011).

In contrast, there are no symptom screening tools available for paediatric cancer patients (Dupuis et al, 2012; Tomlinson et al, 2014). In our previous research, we conducted a systematic review of symptom assessment scales that have been used in paediatric cancer and using focus group methodology, identified that none were ideal for symptom screening (Dupuis et al, 2012; Tomlinson et al, 2014). The overall goal is to develop an electronic symptom screening tool for use in clinical practice. We began the process of item generation using a nominal group technique among paediatric cancer healthcare professionals (Tomlinson et al, 2014). A total of 44 items were generated initially; these were reduced to the 15 items, which were considered the most important for symptom screening based on criteria articulated by the focus group (Tomlinson et al, 2014). With these 15 items, an initial draft of an instrument was developed and named the Symptom Screening in Pediatrics Tool (SSPedi; Tomlinson et al, 2014). The objective of this study was to evaluate and refine the initial iteration of SSPedi using the opinions of children with cancer and parents of paediatric cancer patients.

\section{MATERIALS AND METHODS}

Subjects. Child respondents were patients 8-18 years of age with cancer undergoing active treatment. We included children as young as 8 years of age as we were confident that most children could complete electronic diaries in this age range based on previous work (Palermo et al, 2004; Stinson et al, 2008; Stinson, 2009; Alfven, 2010). Although there will be some children younger than 8 years of age who can complete electronic diaries, we wanted to ensure that most children were able to understand and complete the instrument for the early phase of instrument development. Exclusion criteria were illness severity, cognitive disability or visual impairment that precluded completion of SSPedi according to the primary healthcare team. We excluded children with cognitive disability as we wanted to distinguish between children who did not understand a SSPedi item related to their disability $v s$ a poorly worded item for most children without cognitive disabilities. We excluded children with visual impairment so that child participants could provide feedback on how SSPedi was presented, even if the child could not read well. Parent respondents were parents of eligible children. All participants had to be able to understand English. Parents did not need to be parents of enrolled children although enrolment of a parent and child from the same family was permitted. Sampling was purposive to consider variance by age, underlying diagnosis and gender.

Procedures. Respondents were recruited from The Hospital for Sick Children (SickKids) in Toronto, Canada. This study received Research Ethics Board approval from SickKids and all participants/ guardians provided informed consent or assent as appropriate. Potential respondents were approached in the inpatient or outpatient setting by a member of the study team. Demographic information was obtained from respondents and from the patients' health records. Next, child respondents were invited to complete SSPedi by themselves. Research personnel were present to answer questions in a standardised manner. If children had questions about the meaning of a specific item, a predefined set of synonyms was shown to them. For children who requested greater assistance, SSPedi could be read to them verbatim by research personnel. All assistance provided was recorded. Each parent respondent was asked to complete SSPedi on behalf of their child.

After the child or parent completed SSPedi, he/she then responded to semi-structured questions. Interviews were conducted by trained clinical research associates or nurses with experience in cognitive interviewing. All interviews were audio taped and transcribed. Questions were designed to (i) assess ease of completion; (ii) evaluate understandability using cognitive probing; (iii) assess whether items with two concepts (such as 'feeling scared or worried') should remain as one item or be separated into two different items; and (iv) assess content validity, or importance of each item to children with cancer in terms of how much it bothered them. Details of these questions are included below.

First, child and parent respondents rated how easy or difficult SSPedi was to complete, both overall and for each item, using a five-point Likert scale ranging from $1=$ 'very hard' to $5=$ 'very easy'. Parents estimated their child's ability to complete SSPedi rather than their own experience.

Second, cognitive probing was conducted in children (not parents) to evaluate the understanding of each item and of the response scale. Cognitive interviewing is a technique used to determine a respondent's level of understanding and to elicit their opinions on a certain question or word (Collins, 2003; Drennan, 2003; Willis et al, 2005; Willis, 2005; Irwin et al, 2009; Ahmed et al, 2009; DiBenedetti et al, 2013). Each interview was conducted by one interviewer and one recorder. One interviewer posed questions to determine whether the child understood the meaning of a SSPedi item. Based on those responses, further questions could be used to clarify the child's level of understanding. The recorder listened to the discussion and judged whether the child understood the item using the scale described below. For example, in order to evaluate understanding of 'feeling disappointed or sad', we asked the child what the item meant to him/her and asked for examples of things that might make him/her feel disappointed or sad. Depending on the response, the interviewer could continue to probe, for example, by asking the child to describe the opposite of disappointed or the opposite of sad. The recorder then rated the child's understanding of each item using a four-point Likert scale ranging from $1=$ 'completely incorrect' to $4=$ 'completely correct'. We also evaluated the child's understanding of the response scale by identifying a symptom that the child had indicated as 'a little', 'medium' or 'a lot' of bother to him/her. We asked the child why he/she indicted that amount and not more or less bother. Understanding of the response scale was rated by the recorder on a three-point Likert scale consisting of $1=$ 'not able to distinguish between choices'; $2=$ 'understands some of the differences between choices but some confusion exists'; and $3=$ 'able to distinguish between choices'. 
Third, because some items contained two concepts such as 'feeling scared or worried', we asked respondents whether these concepts should remain together in one item or whether they should be separated into two different items. Fourth, we asked about each item's importance and whether this symptom bothers children with cancer enough to ask about it regularly. Finally, we asked respondents whether there were any items missing from SSPedi.

Each cohort of 10 children and 10 parents (if parents were still being interviewed) were interviewed in parallel. Upon completion of each cohort, the study team reviewed the responses to identify whether the tool should be modified. For example, with the first iteration, responses were reviewed after 20 participants had been enrolled. Additional questions could be added to the script miditeration depending on the findings during cognitive probing. We anticipated that a final version would require two to four iterations for children (20-40 total) and two iterations for parents (20 total). Child recruitment ceased with the first group of 10 children in which modifications were not required.

Defining thresholds for change. Changes to SSPedi were based upon a set of defined change thresholds that focused on child responses rather than parent responses. Thresholds for change were decided a priori and were derived using the opinions of the investigators based on their experience with children with cancer and instrument development. For the questions related to ease of completion and understandability, thresholds were defined for each cohort of 10 children interviewed since changes were implemented for the next cohort of 10 children to address identified concerns. Thresholds for change for these two questions were: at least $20 \%$ ( 2 of 10 ) of children rated the item as hard or very hard to complete/understand and at least 20\% (2 of 10) of children had interviewer ratings of understandability of 'mostly' or 'completely incorrect'. If thresholds were met, the study team considered item modification.

For the questions related to whether items with two concepts should be separated and whether items are important enough to be included in SSPedi, thresholds were defined among all children interviewed on a cumulative basis since changes to the tool were not anticipated to impact on responses. Thresholds for change for these two questions were: at least $60 \%$ of children thought items with two concepts should be separated and if at least $80 \%$ of children rated the item as not bothersome enough to ask about it regularly. If thresholds were met, the study team considered separating the combined item or removing an item from SSPedi.

If either children or parents identified missing items, the team reviewed the item to determine whether respondents should be asked about this item in the next iteration of testing. In this case, respondents in the next iteration were asked 'Do you think 'item' should be included in SSPedi?'. The item was added if at least $40 \%$ of children thought the item should be included. We also considered the situation in which children thought two SSPedi items could be combined, for example 'Headache' and 'Hurt or pain (other than headache)'. If children or parents identified this as a possibility, then a question about combining them was added to the next iteration of testing. Two SSPedi items were combined if at least $60 \%$ (6 of 10$)$ of children thought they should be combined.

Statistics. Each cohort consisted of 10 children and 10 parents (Bordoni et al, 2006; Kushner et al, 2008). A total unweighted SSPedi score was calculated for each administration. Each item's Likert score ranged from 0 (no bother) to 4 (worst bother); Likert scores were summed for a total score that ranged from 0 (none) to 60 (worst possible) when SSPedi contained 15 items. These scores were described using the median and range. Since the number of items could change with each iteration, the scores are presented by iteration.

\section{RESULTS}

Between August 2013 and January 2014, 30 children and 20 parents were recruited for this study. Figure 1 illustrates the flow diagram of patient evaluation and enrolment. After three cohorts of child respondents $(n=30)$ and two cohorts of parent respondents $(n=20)$, no thresholds for change were met and the instrument was considered satisfactory. Table 1 illustrates the demographics of the children and parents presented by cohort. There were four child and parent respondents from the same family. The median total interview time with child participants was 27.6 (interquartile range (IQR) 23.1-31.1) minutes. The median interview time with parent participants was 18.8 (IQR 14.9-22.5) minutes.

Among children, 27 of 30 (90\%) found SSPedi easy or very easy to complete overall; none found SSPedi hard or very hard to complete. The median time required to complete SSPedi was 1.8 (range 0.5-10.1) minutes. Twenty-seven (90\%) children thought the instrument length was 'about right', with 3 children stating that it was 'too long'. Twelve (40\%) asked for clarification around at least one SSPedi item, resulting in presenting or reading of the synonym list for that item. One child asked that a portion of SSPedi be read by the research personnel, while three children required the entire instrument to be read out loud. All children who felt that SSPedi was 'too long' and who asked for the tool to be

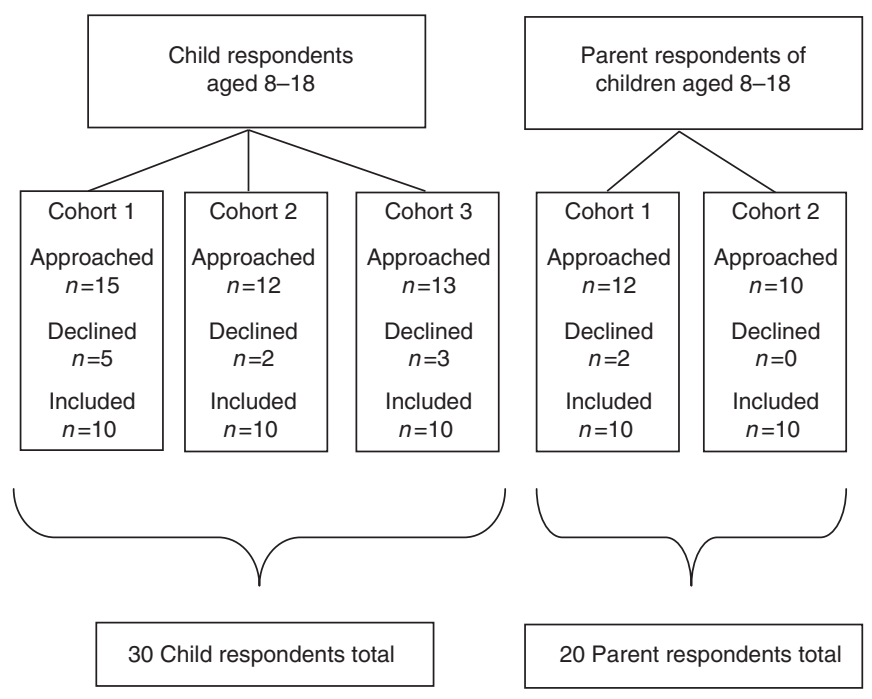

Figure 1. Flow diagram of child and parent identification and enrolment.

\begin{tabular}{|c|c|c|c|c|c|}
\hline & \multicolumn{3}{|c|}{ Children } & \multicolumn{2}{|c|}{ Parents } \\
\hline & $\begin{array}{c}\text { Cohort } 1 \\
(n=10)\end{array}$ & $\begin{array}{c}\text { Cohort } 2 \\
(n=10)\end{array}$ & $\begin{array}{c}\text { Cohort } 3 \\
(n=10)\end{array}$ & $\begin{array}{c}\text { Cohort } 1 \\
(n=10)\end{array}$ & $\begin{array}{c}\text { Cohort } 2 \\
(n=10)\end{array}$ \\
\hline \multicolumn{6}{|c|}{ Age of child in years } \\
\hline $8-10$ & 3 & 6 & 3 & 3 & 4 \\
\hline $11-14$ & 6 & 3 & 3 & 2 & 5 \\
\hline $15-17$ & 1 & 1 & 4 & 5 & 1 \\
\hline Child (male) & 6 & 7 & 7 & 6 & 7 \\
\hline Inpatient & 6 & 8 & 7 & 5 & 8 \\
\hline \multicolumn{6}{|l|}{ Reason for visit } \\
\hline Chemotherapy & 7 & 7 & 9 & 9 & 8 \\
\hline Other & 3 & 3 & 1 & 1 & 2 \\
\hline
\end{tabular}


read out loud were in the $8-10$ year age range. The concept of bother was understood by $30(100 \%)$ and the response options were understood by 26 of 29 (90\%) children (one child did not complete the interview).

Table 2 summarises the results of questions focused on ease or difficulty of completion, understandability, whether items with two concepts should be separated into two questions and whether the item is important enough to children with cancer to include it in SSPedi. Parent responses are illustrated in Appendix 1.
Three items met thresholds for change based upon ease of completion and understandability. 'Changes in how your body or face look' was noted as hard to complete by two children in the second cohort. However, in one child, difficulty related to thinking about the topic rather than understanding the item was noted, and thus the item was not altered. Second, 'Tingly or numb hands or feet' was not understood by two children in cohort 2 . Additional synonyms were added for this item based on how other children described the symptoms. Finally, 'Constipation' was not

\section{Table 2. Results among child respondents for each SSPedi item ${ }^{\mathrm{a}}$}

\begin{tabular}{|c|c|c|c|c|c|c|c|c|}
\hline \multirow{3}{*}{$\begin{array}{l}\text { SSPedi item } \\
\text { Threshold for change } \\
\text { Cohort }^{b}\end{array}$} & \multicolumn{3}{|c|}{$\begin{array}{l}\text { Found very hard or } \\
\text { hard to complete }\end{array}$} & \multicolumn{3}{|c|}{$\begin{array}{l}\text { Completely or mostly } \\
\text { incorrect in understanding }\end{array}$} & \multirow{3}{*}{\begin{tabular}{|l|}
$\begin{array}{c}\text { Combined items } \\
\text { separated }\end{array}$ \\
$\geqslant 18$ of $30(60 \%)$ \\
\end{tabular}} & \multirow{3}{*}{\begin{tabular}{|c|}
$\begin{array}{c}\text { Items not } \\
\text { important }\end{array}$ \\
$\geqslant 24$ of $30(80 \%)$
\end{tabular}} \\
\hline & \multicolumn{3}{|c|}{$\geqslant 2$ of $10(20 \%)$} & \multicolumn{3}{|c|}{$\geqslant 2$ of $10(20 \%)$} & & \\
\hline & 1 & 2 & 3 & 1 & 2 & 3 & & \\
\hline Disappointed or sad & 0 & 0 & 0 & 0 & 0 & 0 & 9 of $30(30 \%)$ & 4 of $30(13 \%)$ \\
\hline Scared or worried & 0 & 0 & 0 & 0 & 0 & 0 & 5 of $30(17 \%)$ & 4 of $30(13 \%)$ \\
\hline Cranky or angry & 0 & 0 & 0 & 1 & 0 & 0 & 4 of $30(13 \%)$ & 6 of $30(20 \%)$ \\
\hline Problems with thinking or remembering & 0 & 0 & 0 & 0 & 1 & 0 & 6 of $30(20 \%)$ & 4 of $30(13 \%)$ \\
\hline Changes in how your body or face look & 0 & 2 & 0 & 1 & 0 & 1 & NA & 6 of $30(20 \%)$ \\
\hline Feeling tired & 0 & 0 & 0 & 0 & 0 & 0 & NA & 4 of $30(13 \%)$ \\
\hline Mouth sores & 0 & 0 & 0 & 0 & 0 & 0 & NA & 3 of $30(10 \%)$ \\
\hline Headache & 1 & 1 & 0 & 0 & 0 & 0 & NA & 5 of $30(17 \%)$ \\
\hline Hurt or pain & 0 & 0 & 1 & 0 & 0 & 0 & 2 of $30(7 \%)$ & 3 of $30(10 \%)$ \\
\hline Tingly or numb hands or feet & 0 & 0 & 0 & 0 & 2 & 0 & 6 of $30(20 \%)$ & 10 of $30(33 \%)$ \\
\hline Throwing up or feeling like you may throw up & 0 & 1 & 0 & 0 & 0 & 0 & 7 of $30(23 \%)$ & 1 of $28(4 \%)$ \\
\hline Feeling more or less hungry than you usually do & 1 & 0 & 1 & 0 & 0 & 1 & 7 of $30(23 \%)$ & 3 of $30(10 \%)$ \\
\hline Constipation & 1 & 1 & 0 & 3 & 1 & 0 & NA & 5 of $30(17 \%)$ \\
\hline Diarrhea & 0 & 0 & 0 & 0 & 1 & 0 & NA & 5 of $30(17 \%)$ \\
\hline Changes in taste & NA & NA & 0 & NA & NA & 0 & NA & 5 of $10(50 \%)$ \\
\hline 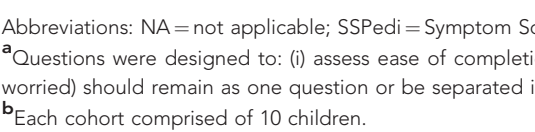 & $\mathrm{ng}$ in $\mathrm{F}$ & & & 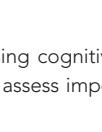 & & . & items with two concepts & $\begin{array}{l}\text { uch as feeling scared o } \\
\text { ther. }\end{array}$ \\
\hline
\end{tabular}

\section{Table 3. Summary of changes to SSPedi by iteration and rationale}

\begin{tabular}{|l|l|l|}
\hline Child respondent & Changes made to the tool & Rationale for change \\
\hline $1-10$ & Reformatting of SSPedi, removed shading of items & $\begin{array}{l}\text { Preference for circles instead of boxes; children confused about } \\
\text { whether shaded items needed to be completed }\end{array}$ \\
\hline & Changed 'Moody' to 'Cranky' & Moody not understood \\
\hline & $\begin{array}{l}\text { Removed 'Sleeping too much or too little' } \\
\text { hungry than you usually do' }\end{array}$ & Considered the same concept as feeling tired \\
\hline & Added descriptors to 'Constipation' and 'Diarrhea' & $\begin{array}{l}\text { Constipation not well understood; added descriptors to diarrhea } \\
\text { for consistency }\end{array}$ \\
\hline $11-20$ & Added detail to synonym list for 'Tingly and numb hands or feet' & Not well understood by younger children \\
\hline & Added 'Changes in taste' & $\begin{array}{l}\text { Identified as a missing item by parents and confirmed as important } \\
\text { by children }\end{array}$ \\
\hline 20-30 & None & \\
\hline Abbreviation: SSPedi $=$ Symptom Screening in Pediatrics Tool. & \\
\hline
\end{tabular}


understood by six children across all cohorts. An additional descriptor '(hard to poop)' was added to the item.

'Changes in taste' was identified as a missing item by a parent respondent in cohort 1 . The last four children in cohort 1 and all children in cohort 2 were asked whether this item should be added to SSPedi. Since 10 of 14 (71\%) child respondents thought this item should be added, the subsequent iteration used in cohort 3 included this SSPedi item. There was also a question about whether 'Headache' and 'Hurt or pain (other than headache)' should be combined based on respondent comments. The last four children in cohort 1 and all children in cohort 2 were asked whether these two items should be combined; 7 of $14(50 \%)$ child respondents thought these items should be combined. Since this result did not meet our threshold for combining two separate items (60\%), they remained as separate items for cohort 3 .

One item was removed after reviewing the responses from cohort 1, namely 'Sleeping too much or too little'. When describing the items 'Sleeping too much or too little' and 'Feeling tired', children provided similar responses qualitatively. When specifically asked during cognitive probing, three of the last five children in cohort 1 stated that the two items are measuring the same thing. The investigative team decided to delete the sleeping item since feeling tired was felt to be more relevant to children while changes in sleeping pattern was felt to be more relevant to parents. Changes to SSPedi and the rationale for these changes are delineated in Table 3.

After review of the data from the 10 children in cohort 3, no further modifications to SSPedi were required. The median (range) SSPedi scores for the three iterations were 10 (2-22), 11 (1-33) and 9 (3-23). Figure 2 illustrates the final paper version of SSPedi.

\section{DISCUSSION}

We successfully developed an initial draft of SSPedi that is easy to complete, understandable and has content validity according to children with cancer. This accomplishment is an important step toward the development of an electronic symptom screening tool

SSPedi: Symptom Screening in Pediatrics

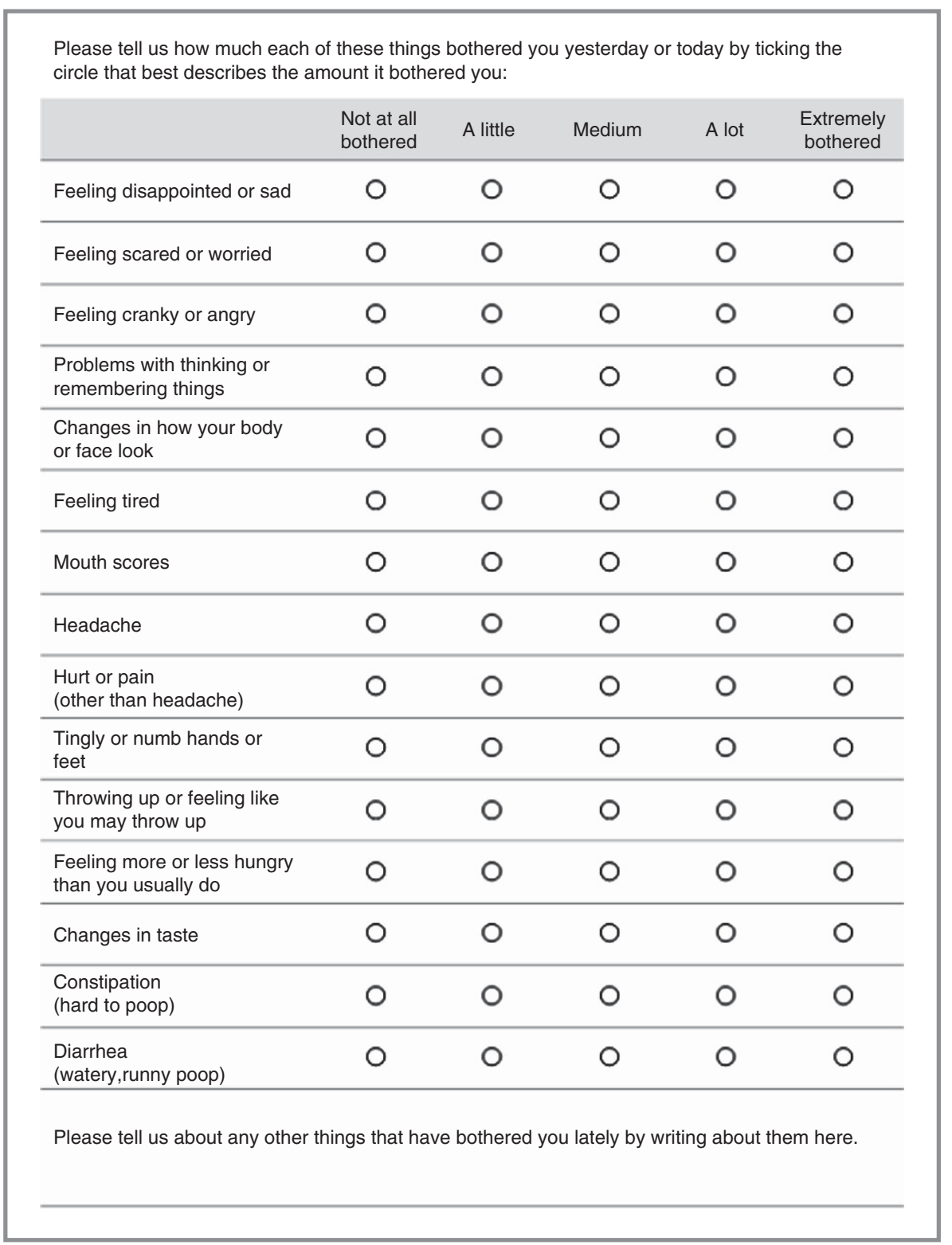

Figure 2. Final version of SSPedi. 
for children with cancer and incorporation of this tool into clinical practice. It is important to emphasise that the primary purpose of this tool will be for symptom screening and not symptom assessment. Many symptom assessment tools exist for children with cancer, some of which are generic (Dupuis et al, 2012; Tomlinson et al, 2014) while others are symptom specific (Hicks et al, 2001; Dupuis et al, 2006; Gilchrist and Tanner, 2013; Jacobs et al, 2013); SSPedi is not intended to replace these instruments.

We learned several important methodological lessons during this study. First, we appreciated that defining thresholds for change a priori is important. This step facilitates decision making when reviewing responses following each iteration, and provides a framework to focus investigator discussions. Second, we recognised the importance of using a multidisciplinary group of healthcare experts, including a parent advocate, to decide on potential modifications to the instrument.

Many children required assistance with reading and needed additional explanation of SSPedi items. We realise that this will be an ongoing issue, particularly with the youngest children. Yet, this is an important challenge to overcome as children are the best reporter of their symptoms and ideally, even young children should be enabled to self-report. In our future work, we plan to offer audio assistance to children, both to read SSPedi out loud and to help them with a specific item if they are unsure of its meaning. Another future goal will be to evaluate and possibly refine SSPedi to allow its use by all children irrespective of age, disability or language. Translation and cross-cultural validation will be important for languages other than English and revision may be required for English-speaking countries outside of North America.

The strength of our study is the rigorous and iterative approach to the early evaluation of SSPedi. However, this report has several limitations including its conduct at a single site. We chose this approach to ensure close oversight over the interview process and data. However, evaluation of the instrument's psychometric properties will be conducted in a multicentre setting. Another limitation is that the number of children interviewed with each iteration was relatively small. We acknowledge that further revisions to SSPedi may be required as the instrument continues to be evaluated in larger cohorts of children.

In summary, we have finalised a paper version of SSPedi, a symptom screening tool for children with cancer. Future work will translate the finalised paper version of SSPedi to an electronic version. The psychometric properties of the final electronic version will then be evaluated in a multicentre setting.

\section{ACKNOWLEDGEMENTS}

This research is funded by The Pedal for Hope Impact Grant of the Canadian Cancer Society (grant \#702295).

\section{CONFLICT OF INTEREST}

The authors declare no conflict of interest.

\section{REFERENCES}

Ahmed N, Bestall JC, Payne SA, Noble B, Ahmedzai SH (2009) The use of cognitive interviewing methodology in the design and testing of a screening tool for supportive and palliative care needs. Support Care Cancer 17(6): 665-673.

Alfven G (2010) SMS pain diary: a method for real-time data capture of recurrent pain in childhood. Acta Paediatr 99(7): 1047-1053.

Baggott C, Dodd M, Kennedy C, Marina N, Matthay KK, Cooper BA, Miaskowski C (2010) Changes in children's reports of symptom occurrence and severity during a course of myelosuppressive chemotherapy. J Pediatr Oncol Nurs 27(6): 307-315.

Bordoni N, Cadile Mdel C, Sotelo R, Squassi A (2006) Teachers' perception of oral health status. Design and validation of an evaluation instrument. Acta Odontol Latinoam 19(2): 67-74.

Bruera E, Kuehn N, Miller MJ, Selmser P, Macmillan K (1991) The Edmonton Symptom Assessment System (ESAS): a simple method for the assessment of palliative care patients. J Palliat Care 7(2): 6-9.

Canadian Cancer Society's Steering Committee on Cancer Statistics Canadian Cancer Statistics 2011. Canadian Cancer Society: Toronto, ON (2011).

Cancer Care Ontario (2011) Ontario Cancer Symptom Management Collaborative.

Carelle N, Piotto E, Bellanger A, Germanaud J, Thuillier A, Khayat D (2002) Changing patient perceptions of the side effects of cancer chemotherapy. Cancer 95(1): 155-163.

Coates A, Abraham S, Kaye SB, Sowerbutts T, Frewin C, Fox RM, Tattersall MH (1983) On the receiving end-patient perception of the side-effects of cancer chemotherapy. Eur J Cancer Clin Oncol 19(2): 203-208.

Collins D (2003) Pretesting survey instruments: an overview of cognitive methods. Qual Life Res 12(3): 229-238.

de Boer-Dennert M, de Wit R, Schmitz PI, Djontono J, v Beurden V, Stoter G, Verweij J (1997) Patient perceptions of the side-effects of chemotherapy: the influence of 5HT3 antagonists. Br J Cancer 76(8): 1055-1061.

DiBenedetti DB, Price MA, Andrews EB (2013) Cognitive interviewing in risk minimization survey development: patient and healthcare professional surveys. Expert Rev Clin Pharmacol 6(4): 369-373.

Drennan J (2003) Cognitive interviewing: verbal data in the design and pretesting of questionnaires. J Adv Nurs 42(1): 57-63.

Dupuis LL, Taddio A, Kerr EN, Kelly A, MacKeigan L (2006) Development and validation of the pediatric nausea assessment tool for use in children receiving antineoplastic agents. Pharmacotherapy 26(9): 1221-1231.

Dupuis LL, Tomlinson D, Ethier MC, Hesser T, Sung L (2012) A systematic review of symptom assessment scales in children with cancer. BMC Cancer 12(1): 430.

Gibson F, Aldiss S, Taylor RM, Maguire R, McCann L, Sage M, Kearney N (2010) Utilization of the Medical Research Council evaluation framework in the development of technology for symptom management: the ASyMS-YG Study. Cancer Nurs 33(5): 343-352.

Gilchrist LS, Tanner L (2013) The pediatric-modified total neuropathy score: a reliable and valid measure of chemotherapy-induced peripheral neuropathy in children with non-CNS cancers. Support Care Cancer 21(3): $847-856$.

Griffin AM, Butow PN, Coates AS, Childs AM, Ellis PM, Dunn SM, Tattersall MH (1996) On the receiving end. V: Patient perceptions of the side effects of cancer chemotherapy in 1993. Ann Oncol 7(2): 189-195.

Hicks CL, von Baeyer CL, Spafford PA, van Korlaar I, Goodenough B (2001) The Faces Pain Scale-Revised: toward a common metric in pediatric pain measurement. Pain 93(2): 173-183.

Irwin DE, Varni JW, Yeatts K, DeWalt DA (2009) Cognitive interviewing methodology in the development of a pediatric item bank: a patient reported outcomes measurement information system (PROMIS) study. Health Qual Life Outcomes 7: 3.

Jacobs S, Baggott C, Agarwal R, Hesser T, Schechter T, Judd P, Tomlinson D, Beyene J, Sung L (2013) Validation of the Children's International Mucositis Evaluation Scale (ChIMES) in paediatric cancer and SCT. Br J Cancer 109(10): 2515-2522.

Kushner JA, Lawrence HP, Shoval I, Kiss TL, Devins GM, Lee L, Tenenbaum HC (2008) Development and validation of a Patient-Reported Oral Mucositis Symptom (PROMS) scale. J Can Dent Assoc 74(1): 59.

Miller E, Jacob E, Hockenberry MJ (2011) Nausea, pain, fatigue, and multiple symptoms in hospitalized children with cancer. Oncol Nurs Forum 38(5): E382-E393.

Oeffinger KC, Mertens AC, Sklar CA, Kawashima T, Hudson MM, Meadows AT, Friedman DL, Marina N, Hobbie W, Kadan-Lottick NS, Schwartz CL, Leisenring W, Robison LL (2006) Chronic health conditions in adult survivors of childhood cancer. $N$ Engl J Med 355(15): $1572-1582$.

Palermo TM, Valenzuela D, Stork PP (2004) A randomized trial of electronic versus paper pain diaries in children: impact on compliance, accuracy, and acceptability. Pain 107(3): 213-219. 
Poder U, Ljungman G, von Essen L (2010) Parents' perceptions of their children's cancer-related symptoms during treatment: a prospective, longitudinal study. J Pain Symptom Manage 40(5): 661-670.

Stinson JN (2009) Improving the assessment of pediatric chronic pain: harnessing the potential of electronic diaries. Pain Res Manag 14(1): 59-64.

Stinson JN, Stevens BJ, Feldman BM, Streiner D, McGrath PJ, Dupuis A, Gill N, Petroz GC (2008) Construct validity of a multidimensional electronic pain diary for adolescents with arthritis. Pain 136(3): 281-292.

Tomlinson D, Dupuis LL, Gibson P, Johnston DL, Portwine C, Baggott C, Zupanec S, Watson J, Spiegler B, Kuczynski S, Macartney G, Sung L (2014) Initial development of the Symptom Screening in Pediatrics Tool (SSPedi). Support Care Cancer 22(1): 71-75.

Willis G, Reeve B, Barofsky I (2005) The use of cognitive interviewing techniques in quality of life and patient reported outcomes assessment.
In: Outcomes Assessment in Sancer: Measures, Methods, and Applications, Lipscomb J, Gotay C, Snyder C (eds). Cambridge University Press:

Cambridge, UK, pp 610-622.

Willis GB (2005) Cognitive Interviewing: a Tool for Improving Questionnaire Design. Sage Publications: Thousand Oaks, Calif.

Woodgate RL (2003) The 2002 Schering Lecture. Children's cancer symptom experiences: keeping the spirit alive in children and their families. Can Oncol Nurs J 13(3): 142-150.

This work is published under the standard license to publish agreement. After 12 months the work will become freely available and the license terms will switch to a Creative Commons AttributionNonCommercial-Share Alike 3.0 Unported License.

APPENDIX 1

Table A1. Summary of responses among parent respondents

\begin{tabular}{|c|c|c|c|c|c|c|}
\hline \multirow{3}{*}{$\begin{array}{l}\text { SSPedi Item } \\
\text { Threshold for change } \\
\text { Cohort }^{\mathrm{a}}\end{array}$} & \multicolumn{2}{|c|}{$\begin{array}{l}\text { Found very hard or } \\
\text { hard to complete }\end{array}$} & \multicolumn{2}{|c|}{$\begin{array}{l}\text { Completely or mostly } \\
\text { incorrect in understanding }\end{array}$} & \multirow{3}{*}{$\begin{array}{l}\begin{array}{c}\text { Combined items } \\
\text { separated }\end{array} \\
\geqslant 12 \text { of } 20(60 \%)\end{array}$} & \multirow{3}{*}{$\begin{array}{c}\begin{array}{c}\text { Items not } \\
\text { important }\end{array} \\
\geqslant 16 \text { of } 20(80 \%)\end{array}$} \\
\hline & \multicolumn{2}{|c|}{$\geqslant 2$ of $10(20 \%)$} & \multicolumn{2}{|c|}{$\geqslant 2$ of $10(20 \%)$} & & \\
\hline & 1 & 2 & 1 & 2 & & \\
\hline Disappointed or sad & 0 & 0 & 0 & 0 & 11 of $20(55 \%)$ & 2 of $20(10 \%)$ \\
\hline Scared or worried & 0 & 1 & 0 & 0 & 3 of $20(15 \%)$ & 1 of $20(5 \%)$ \\
\hline Cranky or angry & 1 & 0 & 0 & 0 & 5 of $20(25 \%)$ & 1 of $20(5 \%)$ \\
\hline Problems with thinking or remembering & 0 & 1 & 0 & 0 & 3 of $20(15 \%)$ & 1 of $20(5 \%)$ \\
\hline Changes in how your body or face look & 1 & 0 & 0 & 0 & NA & 1 of $20(5 \%)$ \\
\hline Feeling tired & 0 & 0 & 0 & 0 & NA & 0 of $20(0 \%)$ \\
\hline Mouth sores & 0 & 0 & 0 & 1 & NA & 1 of $20(5 \%)$ \\
\hline Headache & 0 & 0 & 0 & 0 & NA & 0 of $20(0 \%)$ \\
\hline Hurt or pain & 0 & 0 & 0 & 0 & 4 of $20(20 \%)$ & 0 of $20(0 \%)$ \\
\hline Tingly or numb hands or feet & 1 & 0 & 3 & 1 & 1 of $20(5 \%)$ & 0 of $20(0 \%)$ \\
\hline Throwing up or feeling like you may throw up & 0 & 0 & 0 & 0 & 1 of $20(5 \%)$ & 1 of $20(5 \%)$ \\
\hline Feeling more or less hungry than you usually do & 1 & 0 & 0 & 0 & 1 of $20(5 \%)$ & 4 of $20(20 \%)$ \\
\hline Constipation & 1 & 0 & 1 & 0 & NA & 2 of $20(10 \%)$ \\
\hline Diarrhea & 0 & 0 & 0 & 0 & NA & 0 of $20(0 \%)$ \\
\hline
\end{tabular}

